\title{
Kombinasi Backpropagation dan Hopfield Modifikasi untuk Persamaan Polynomial
}

\author{
Rina Pramitasari ${ }^{1}$, Imam Rofiki ${ }^{2}$ \\ ${ }^{1}$ Teknik Komputer, Universitas Amikom Yogyakarta, Yogyakarta, Indonesia \\ rina.pramitasari@amikom.ac.id \\ ${ }^{2}$ Tadris Matematika, Universitas Islam Negeri Maulana Malik Ibrahim, Malang, Indonesia \\ imam.rofiki@uin-malang.ac.id
}

Diterima 23 Mei 2020

Disetujui 23 Juni 2020

\begin{abstract}
Salah satu sistem kriptografi yang bertahan di era komputer quantum adalah kriptografi kunci publik multivariat. Tingkat keamanan sistem kriptografi kunci publik multivariat adalah sulitnya menyelesaikan sistem persamaan polinomial multivariable. Tujuan artikel adalah mengkriptanalisis dengan mencari akar menyelesaikan persamaan polinomial. Penelitian ini menggunakan metode kombinasi Backpropagarian dan Hopfield Modifikasi. Hasil penelitian menunjukkan bahwa metode kombinasi Backpropagarian dan Hopfield Modifikasi lebih baik dari pada metode Hopfield Modifikasi saja. Karena menjamin nilai awal yang diberikan pada Hopfield Modifikasi selalu dekat dengan nilai solusi. Metode kombinasi Backpropagarian dan Hopfield Modifikasi memberikan solusi yang akurat.
\end{abstract}

Index Terms-Backpropagation, Hopfield Network Modifikasi, Persamaan Polinomial

\section{PENDAHULUAN}

Sistem kriptografi kunci publik yang paling banyak digunakan adalah RSA. Algoritme RSA berasal dari nama akhir penemunya pada tahun 1977, yaitu Rivest-Shamir-Adleman. Tingkat keamanan RSA terletak pada faktorisasi bilangan bulat. Kunci publik yang aman pada RSA setidaknya 1024 bits atau 2048 bits. Hal ini mengakibatkan proses enkripsi tidak efisien. Ancaman baru juga muncul yang bisa melemahkan RSA yaitu komputer quantum yang sedang berkembang. Ada beberapa kandidat sistem kriptografi yang mampu bertahan dengan komputer quantum yaitu Lattice-Based Cryptography, CodeBased Cryptography, Multivariate-Based Cryptography [4], [7], [8], [11].

Pengujian sistem kriptografi salah satunya adalah dengan menggunakan kriptanalisis. Sistem kriptografi kunci publik atau sistem kriptografi asimetris, menggunakan dua jenis kunci, yaitu kunci publik dan kunci rahasia. Kunci publik digunakan untuk mengenkripsi suatu pesan. Kunci publik bersifat umum, sehingga dapat dilihat oleh semua orang termasuk pihak penyerang. Kunci rahasia digunakan untuk mendekripsi suatu pesan. Kunci rahasia bersifat dirahasiakan dan hanya orang tertentu yang boleh mengetahuinya [7].

Sistem kriptografi kunci publik multivariat didasarkan pada sistem persamaan multivariable nonlinear pada bidang hingga. Tingkat keamanan didasarkan pada sulitnya penyelesaian sebuah sistem persamaan polynomial multivariable kuadratik yang disebut MQ-problem (multivariate quadratic problem) [4], [7], [8], [11].

Menyelesaikan sistem persamaan nonliner bentuk yang sederhana dapat diselesaikan dengan metode analitik. Sedangkan faktanya sering menemukan bentuk yang rumit, tidak semua persamaan dapat dipecahkan dengan metode analitik, maka solusinya dapat dicari dengan metode numerik. Sedangkan metode numerik harus memenuhi syarat dekat dengan solusi untuk bisa konvergen. Maka untuk menyelesaikan sistem persamaan tersebut digunakan jaringan saraf tiruan di mana sebuah prosesor yang terdistribusi parallel dan mempunyai kecenderungan untuk menyimpan pengetahuan yang didapatkannya dari pengalaman dan membuatnya tetap tersedia untuk digunakan [9].

Jariangan Backpropagation diambil dari cara kerja yaitu bahwa gradien error unit-unit tersembunyi diturunkan dari penyiaran kembali error yang diasosiasikan dengan unit output. Hal ini karena nilai target untuk unit-unit tersembunyi tidak diberikan [2].

Jaringan Hopfield pertama kali diperkenalkan John Hopfield pada tahun 1982. Jaringan Hopfield adalah pelatihantak terbimbing (unsupervised learning). Jaringan Hopfield merupakan jaringan syaraf tiruan yang terhubung penuh (fully connected), yaitu bahwa setiap neuron terhubung dengan neuron lainnya [2]. Jaringan Hopfield Modifikasi mampu untuk menyelesaikan sistem persamaan nonlinear di dalam satu variabel. Hasil penelitian menunjukkan bahwa jaringan Hopfield modifikasi akan selalu konvergen terhadap sembarang nilai awal, dimana sebaliknya metode numerik yang harus memenuhi syarat "dekat" dengan solusi [1], [6]. 


\section{LANDASAN TEORI}

\section{A. Persamaan Polynomial}

Persoalan mencari solusi persamaan nonlinear adalah: Tentukan nilai x yang memenuhi persamaan.

$$
f(x)=0
$$

yaitu nilai $x=s$ sedemikian sehingga $f(s)$ sama dengan nol [9]. Persamaan nonlinear yang melibatkan fungsi transeden, diantaranya sinus, cosinus, eksponensial, logaritma. Selain itu, persamaan nonlinear yang tidak melibatkan fungsi transenden, yaitu persamaan polynomial. Bentuk umum persamaan polynomial satu variabel $\mathrm{x}$ adalah

$$
a_{n} x^{n}+a_{n-1} x^{n-1}+\cdots+a_{1} x+a_{0}=0
$$

Contohnya:

a. Satu variabel yaitu $x$,

$$
4 x^{5}+9 x^{3}+2 x-5=0
$$

b. Dua variabel yaitu $x$ dan $y$,

$$
3 x^{2}+9 x y-y=0
$$

Pada peneltian ini, penulis menggunakan satu variabel.

\section{B. Backpropagation}

Backpropagation adalah metode yang menurukan gradien untuk meminimkan penjumlahan error kuadrat output jaringan. Nama lain dari Backpropagation adalah aturan delta yang digeneralisasi.

Dalam Backpropagation, setiap unit yang berbeda di lapisan input terhubung dengan setiap unit yang ada di lapisan tersembunyi. Hal serupa berlaku pula pada lapisan tersembunyi. Setiap unit yang ada di lapisan tersembunyi terhubung dengan setiap unit yang ada di lapisan output [3], [5], [6].

Langkah Backpropagation adalah sebagai berikut:

- Inisialisasi bobot dan bias

1. While kondisi berhenti tidak terpenuhi do langkah ke-2 sampai langkah ke-9.

2. Untuk setiap pasang pola training, lakukan langkah ke-3 sampai langkah ke-8.

- Umpan Maju (Feedforward)

3. Setiap unit input, mengirimkan sinyal input ke semua unit pada lapisan tersembunyi.

4. Pada setiap unit di lapisan tersembunyi, sinyal input output lapisan tersembunyi dihitung dengan dengan fungis aktivasi terhadap penjumlahan sinyal input berbobot.

5. Pada setiap unit di lapisan output unit, dihitung sinyal output-nya dengan menerapkan fungsi aktivasi terhadapt penjumlahan sinyal input berbobot.

- Umpan Mundur (Backpropagation Error)

6. Pada setiap unit output menerima pola target lalu informasi kesalahan lapisan output dihitung. Dikirim ke lapisan di bawahnya dan digunakan untuk menghitung besar koreksi bobot dan bias antara lapisan tersembunyi dengan lapisan output.

7. Pada setiap unit di lapisan tersembunyi dilakukan perhitungan informasi kesalahan lapisan tersembunyi. Kemudian digunakan untuk menghitung besar koreksi bobot dan bias antara lapisan input dan lapisan tersembunyi.

- Update Bobot dan Bias (Adjustment)

8. Pada setiap unit output, dilakukan pengupdate-an bias dan bobot.

9. Tes kondisi berhenti. Digunakan kriteria MSE (Mean Square Error).

\section{Hopfield Modifikasi}

Hopfield mengembangkan rancangan jaringan biner sehingga neuron dapat memperhitungkan nilai real [3]. Pengembangan dari jaringan Hopfield Kontinu adalah menyerupai kerja jaringan diskrit, tetapi jaringan ini mempunyai kemampuan lebih karena arsitekturnya lebih komplek dan tidak hanya nilai biner 0 dan 1 [1].

Hopfield Modifikasi didasarkan pada prinsip Hopfield kontinu, karena nilai input dan output yang diinginkan adalah real antara 0 sampai 1 , tidak hanya 0 atau 1. Jumlah neuron pada jaringan sama dengan jumlah variabel persamaan. Hubungan antara neuron pada Hopfield Modifikasi untuk menyelesaikan persamaan polynomial bergantung pada hubungan antara variabel persamaan dengan koefisien, yang diturunkan sebagai bobot pada jaringan. Hubungan antara variabel pada persamaan polynomial adalah hubungan nonlinear, sehingga jaringan Hopfield harus dimodifikasi [1].

Langkah-langkah Hopfield Modifikasi adalah sebagai berikut:

1. Mengubah persamaan polynomial menjadi bentuk fungsi energi.

$$
\begin{gathered}
g_{i}(.)=\left(f_{i}\left(x_{1}, \cdots, x_{j}, \ldots, x_{n}\right)+\left(-P_{i}\right)\right) \\
E=-\frac{1}{2} \sum_{i=1}^{m}\left(g_{i}()\right)^{2}
\end{gathered}
$$


2. Menurunkan persamaan fungsi energi.

$$
\frac{d u_{j}}{d t}=\frac{\partial E}{\partial x_{j}}
$$

3. Kemudian menyesuaikan dengan persamaan Hopfield.

$$
\sum_{i} W_{j 1} f_{j 1}\left(x_{1}, x_{2}, \cdots, x_{n}\right)+I_{j}, \quad(i, j) \in n
$$

4. Menginisialisasi nilai awal $x(1)$ dan $u(1)$.

5. Menghitung dengan metode Euler untuk memperbaiki nilai $u(t)$.

$$
u(t+1)=u_{j}(t)+\Delta t\left(\frac{\partial E}{\partial x_{i}}\right)
$$

6. Memperbarui nilai $x(t)$.

$$
x(t)=\frac{1}{1+e^{-W[t]}}
$$

7. Hingga syarat terpenuhi.

\section{Metode Penelitian}

Gambar 1 menunjukan flowchart penelitian. Langkah pertama, dengan menggunakan metode Backpropagation didapat nilai output yang optimal. Langkah kedua, menggunakan nilai output untuk memberilkan nilai awal pada metode Hopfield Modifikasi untuk menyelesaikan persamaan polynomial [10]. Hasil penelitian akan dibandingkan dengan metode Hopfield Modifikasi dan metode konvensional yaitu metode numerik Newton Raphson.

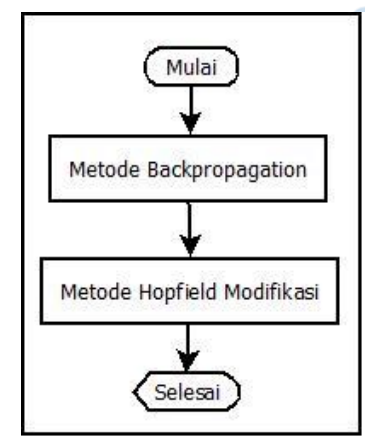

Gambar 1. Flowchart penelitian

Misalkan persamaan polynomial berbentuk:

$$
A x^{2}+B x+C=0
$$

Proses Backpropagation menggunakan layer input 3 neuron, layer hidden 10 neuron, dan layer output 1 neuron. Fungsi aktivasi yang digunakan adalah Sigmoid Biner dan learning rate $\left({ }^{\infty}\right)=0,5$. Epoch $=$ 10000. Toleransi error yang digunakan adalah 0,000000000000001.
Proses Hopfield Modifikasi adalah:

1. Mengubah persamaan polynomial menjadi bentuk fungsi energi.

$$
\begin{gathered}
A x^{2}+B x+C=0 \\
E=-\frac{1}{2} \sum_{i=1}^{m}\left(g_{i}(D)\right)^{2} \\
E=-\frac{1}{2}\left(A x^{2}+B x+C\right)^{2}
\end{gathered}
$$

2. Menurunkan persamaan fungsi energi.

$$
\begin{gathered}
\frac{d u_{j}}{d t}=\frac{\partial E}{\partial x_{j}} \\
=-\left(2 A^{2} x^{3}+(A B+2 A B) x^{2}+\left(B^{2}+2 A C\right) x+B C\right)
\end{gathered}
$$

3. Kemudian menyesuaikan dengan persamaan Hopfield.

$$
\begin{gathered}
\frac{d u}{d t}=W_{1} x^{3}+W_{2} x^{2}+W_{3} x+I_{\text {bins }} \\
W_{1}=2 A^{2}, W_{2}=A B+2 A B x \\
W_{3}=B^{2}+2 A C, I_{\text {bins }}=B C
\end{gathered}
$$

4. Menginisialisasi nilai awal $x(1)$ adalah hasil dari Backpropagation dan $u(1)$ adalah $-0.5,1$, atau 0.01 .

5. Menghitung dengan metode Euler untuk memperbaiki nilai $u(t)$.

$u(t+1)=u(t)+\Delta t\left(W_{1} x_{t}^{a}+W_{2} x_{t}^{2}+W_{3} x_{t}+I_{\text {bias }}\right)$

6. Memperbarui nilai $x(t)$

$$
x(t)=\frac{1}{1+e^{-u[t]}}
$$

7. Hingga syarat terpenuhi.

\section{PEMBAHASAN}

Dalam pembahasan menggunakan pemrograman Python. Kemudian menyiapkan data pelatihan dan data pengujian dengan merujuk penelitian [1], [4], [7], [12]

Data pelatihan terdiri dari 2 bentuk persamaan yaitu Pertama berbentuk:

$$
A x^{2}+B x+C=0
$$

Jumlah dari data pelatihan terdiri dari 10 dan 20 data. Data pengujian tersebut terdiri dari 3 persamaan yaitu:

$$
\begin{aligned}
& x^{2}-0.0324=0 \text { dengan Output } 0.18 \\
& x^{2}-0.3364=0 \text { dengan Output } 0.58 \\
& x^{2}-0.9604=0 \text { dengan Output } 0.98
\end{aligned}
$$


Jaringan Backpropagation menggunakan layer input 3 neuron, layer hidden 10 neuron, dan layer output 1 neuron. Fungsi aktivasi yang digunakan adalah Sigmoid Biner dan learning rate $(\propto)=0,5$. Epoch $=10000$. Toleransi error yang digunakan adalah 0,000000000000001.

Kedua berbentuk:

$$
A x^{4}+B x^{3}+C x^{2}+D x+E=0
$$

Jumlah dari data pelatihan terdiri dari 10 dan 20 data. Data pengujian tersebut terdiri dari 3 persamaan yaitu:

$$
x^{4}+x^{3}-0.0324 x-0.00104976=0
$$

dengan Output 0.18

$$
x^{4}+x^{3}-0.3364 x-0.11316496=0
$$

dengan Output 0.58

$$
x^{4}+x^{3}-0.9604 x-0.92236816=0
$$

dengan Output 0.98

Jaringan Backpropagation menggunakan layer input 5 neuron, layer hidden 10 neuron, dan layer output 1 neuron, Fungsi aktivasi yang digunakan adalah Sigmoid Biner dan learning rate $(\kappa)=0,5$. Epoch $=10000$. Toleransi error yang digunakan adalah 0,000000000000001.

Kemudian melakukan proses perhitungan jaringan Hopfield Modifikasi berdasarkan berbedaan nilai $u(t)$. Nilai $u(t)$ yang dipilih adalah $-0.5,1$, dan 0.01 .

Tabel 1. Hasil pengujian dengan persamaan

$$
x^{2}-0.0324=0
$$

\begin{tabular}{|c|c|c|c|}
\hline \multicolumn{4}{|c|}{ Dengan 10 Training Data } \\
\hline U1 & X akhir & Iterasi & Error \\
\hline-0.5 & 0.1800000045 & 840 & 0.0 \\
\hline 1 & 0.1800000045 & 845 & 0.0 \\
\hline 0.01 & 0.1800000046 & 842 & 0.0 \\
\hline \multicolumn{4}{|c|}{ Dengan 20 Training Data } \\
\hline U1 & X akhir & Iterasi & Error \\
\hline-0.5 & 0.1800000045 & 840 & 0.0 \\
\hline 1 & 0.1800000045 & 845 & 0.0 \\
\hline 0.01 & 0.1800000046 & 842 & 0.0 \\
\hline
\end{tabular}

Tabel 2. Hasil pengujian dengan persamaan

$$
x^{2}-0.3364=0
$$

\begin{tabular}{|c|c|c|c|}
\hline \multicolumn{5}{|c|}{ Dengan 10 Training Data } \\
\hline $\boldsymbol{U 1}$ & $\mathbf{X}$ akhir & Iterasi & Error \\
\hline-0.5 & 0.5799999999 & 58 & 0.0 \\
\hline 1 & 0.5800000001 & 54 & 0.0 \\
\hline 0.01 & 0.5799999999 & 54 & 0.0 \\
\hline
\end{tabular}

\begin{tabular}{|c|c|c|c|}
\hline \multicolumn{4}{|c|}{ Dengan 20 Training Data } \\
\hline $\boldsymbol{U 1}$ & $\mathbf{X}$ akhir & Iterasi & Error \\
\hline-0.5 & 0.57999999999 & 58 & 0.0 \\
\hline 1 & 0.5800000001 & 54 & 0.0 \\
\hline 0.01 & 0.57999999999 & 54 & 0.0 \\
\hline
\end{tabular}

Tabel 3. Hasil pengujian dengan persamaan

$$
x^{2}-0.9604=0
$$

\begin{tabular}{|c|c|c|c|}
\hline \multicolumn{5}{|c|}{ Dengan 10 Training Data } \\
\hline $\boldsymbol{U 1}$ & X akhir & Iterasi & Error \\
\hline-0.5 & 0.979999999 & 218 & 0.0 \\
\hline 1 & 0.9799999991 & 217 & 0.0 \\
\hline 0.01 & 0.9799999989 & 216 & 0.0 \\
\hline \multicolumn{5}{|c|}{ Dengan 20 Training Data } \\
\hline $\boldsymbol{U 1}$ & X akhir & Iterasi & Error \\
\hline-0.5 & 0.979999999 & 218 & 0.0 \\
\hline 1 & 0.979999999 & 216 & 0.0 \\
\hline 0.01 & 0.9799999988 & 215 & 0.0 \\
\hline
\end{tabular}

Tabel 4. Hasil pengujian dengan persamaan

$$
x^{4}+x^{3}-0.0324 x-0.00104976=0
$$

\begin{tabular}{|c|c|c|c|}
\hline \multicolumn{5}{|c|}{ Dengan 10 Training Data } \\
\hline U1 & X akhir & Iterasi & Error \\
\hline-0.5 & 0.1839713339 & 8865 & 0.0 \\
\hline 1 & 0.1839713265 & 8875 & 0.0 \\
\hline 0.01 & 0.1839713339 & 8870 & 0.0 \\
\hline \multicolumn{4}{|c|}{ Dengan 20 Training Data } \\
\hline U1 & X akhir & Iterasi & Error \\
\hline-0.5 & 0.1839713339 & 8865 & 0.0 \\
\hline 1 & 0.1839713265 & 8875 & 0.0 \\
\hline 0.01 & 0.1839713339 & 8870 & 0.0 \\
\hline
\end{tabular}

Tabel 5. Hasil pengujian dengan persamaan $x^{4}+x^{3}-0.3364 x-0.11316496=0$

\begin{tabular}{|c|c|c|c|}
\hline \multicolumn{5}{|c|}{ Dengan 10 Training Data } \\
\hline $\boldsymbol{U 1}$ & X akhir & Iterasi & Error \\
\hline-0.5 & 0.5799851742 & 41 & 0.0 \\
\hline 1 & 0.5799851742 & 33 & 0.0 \\
\hline 0.01 & 0.5799851742 & 34 & 0.0 \\
\hline \multicolumn{5}{|c|}{ Dengan 20 Training Data } \\
\hline $\boldsymbol{U 1}$ & X akhir & Iterasi & Error \\
\hline-0.5 & 0.5799851742 & 41 & 0.0 \\
\hline 1 & 0.5799851742 & 33 & 0.0 \\
\hline 0.01 & 0.5799851741 & 32 & 0.0 \\
\hline
\end{tabular}


Tabel 6. Hasil pengujian dengan persamaan $x^{4}+x^{3}-0.9604 x-0.92236816=0$

\begin{tabular}{|c|c|c|c|}
\hline \multicolumn{5}{|c|}{ Dengan 10 Training Data } \\
\hline $\boldsymbol{U 1}$ & X akhir & Iterasi & Error \\
\hline-0.5 & 0.980001311 & 21 & 0.0 \\
\hline 1 & 0.980001311 & 19 & 0.0 \\
\hline 0.01 & 0.980001311 & 19 & 0.0 \\
\hline \multicolumn{5}{|c|}{ Dengan 20 Training Data } \\
\hline $\boldsymbol{U 1}$ & X akhir & Iterasi & Error \\
\hline-0.5 & 0.9800013111 & 20 & 0.0 \\
\hline 1 & 0.9800013111 & 20 & 0.0 \\
\hline 0.01 & 0.980001311 & 21 & 0.0 \\
\hline
\end{tabular}

Pada Tabel 1 sampai 6 menunjukkan hasil akar persamaan polinomial dari jumlah data pelatihan 10 dan 20 dan jumlah data pengujian $0.18,0.58,0.98$.

Tabel 7. Hasil pengujian Hopefield Modifikasi dengan persamaan $x^{2}-0.0324=0$

\begin{tabular}{|c|c|c|c|c|}
\hline \multicolumn{5}{|c|}{ Metode Hopfield Modifikasi } \\
\hline X1 & U1 & X akhir & Iterasi & Error \\
\hline-2.05 & -0.5 & 0.1800000046 & 852 & 0.0 \\
\hline 0.11 & -0.5 & 0.1800000045 & 840 & 0.0 \\
\hline 1.65 & -0.5 & - & - & - \\
\hline-2.05 & 1 & 0.1800000045 & 854 & 0.0 \\
\hline 0.11 & 1 & 0.1800000045 & 845 & 0.0 \\
\hline 1.65 & 1 & - & - & - \\
\hline-2.05 & 0.01 & 0.1800000042 & 857 & 0.0 \\
\hline 0.11 & 0.01 & 0.1800000046 & 842 & 0.0 \\
\hline 1.65 & 0.01 & - & - & - \\
\hline
\end{tabular}

Tabel 8. Hasil pengujian Hopefield Modifikasi dengan persamaan $x^{2}-0.3364=0$

\begin{tabular}{|c|c|c|c|c|}
\hline \multicolumn{5}{|c|}{ Metode Hopfield Modifikasi } \\
\hline X1 & U1 & X akhir & Iterasi & Error \\
\hline-2.05 & -0.5 & 0.5800000002 & 64 & 0.0 \\
\hline 0.11 & -0.5 & 0.5799999999 & 57 & 0.0 \\
\hline 1.65 & -0.5 & 0.5799999999 & 6514 & 0.0 \\
\hline-2.05 & 1 & 0.5800000002 & 65 & 0.0 \\
\hline 0.11 & 1 & 0.5800000001 & 54 & 0.0 \\
\hline 1.65 & 1 & 0.5799999999 & 1507 & 0.0 \\
\hline-2.05 & 0.01 & 0.5800000001 & 66 & 0.0 \\
\hline 0.11 & 0.01 & 0.5799999999 & 53 & 0.0 \\
\hline 1.65 & 0.01 & 0.5799999998 & 3938 & 0.0 \\
\hline
\end{tabular}

Tabel 9. Hasil pengujian Hopefield Modifikasi dengan persamaan $x^{2}-0.9604=0$

\begin{tabular}{|c|c|c|c|c|}
\hline \multicolumn{5}{|c|}{ Metode Hopfield Modifikasi } \\
\hline X1 & U1 & X akhir & Iterasi & Error \\
\hline-2.05 & -0.5 & 0.9800000012 & 326 & 0.0 \\
\hline 0.11 & -0.5 & 0.9799999989 & 217 & 0.0 \\
\hline 1.65 & -0.5 & 0.9799999989 & 510 & 0.0 \\
\hline-2.05 & 1 & 0.9800000013 & 344 & 0.0 \\
\hline 0.11 & 1 & 0.979999999 & 216 & 0.0 \\
\hline 1.65 & 1 & 0.9799999989 & 285 & 0.0 \\
\hline-2.05 & 0.01 & 0.980000001 & 335 & 0.0 \\
\hline 0.11 & 0.01 & 0.9799999988 & 215 & 0.0 \\
\hline 1.65 & 0.01 & 0.9799999991 & 2397 & 0.0 \\
\hline
\end{tabular}

Tabel 10. Hasil pengujian Hopefield Modifikasi dengan persamaan

$$
x^{4}+x^{3}-0.0324 x-0.00104976=0
$$

\begin{tabular}{|c|c|c|c|c|}
\hline \multicolumn{5}{|c|}{ Metode Hopfield Modifikasi } \\
\hline X1 & U1 & X akhir & Iterasi & Error \\
\hline-2.05 & -0.5 & - & - & - \\
\hline 0.11 & -0.5 & 0.1839713339 & 8865 & 0.0 \\
\hline 1.65 & -0.5 & - & - & - \\
\hline-2.05 & 1 & - & - & - \\
\hline 0.11 & 1 & 0.1839713265 & 8875 & 0.0 \\
\hline 1.65 & 1 & - & - & - \\
\hline-2.05 & 0.01 & - & - & - \\
\hline 0.11 & 0.01 & 0.1839713339 & 8870 & 0.0 \\
\hline 1.65 & 0.01 & - & - & - \\
\hline
\end{tabular}

Tabel 11. Hasil pengujian Hopefield Modifikasi dengan persamaan

$$
x^{4}+x^{3}-0.3364 x-0.11316496=0
$$

\begin{tabular}{|c|c|c|c|c|}
\hline \multicolumn{5}{|c|}{ Metode Hopfield Modifikasi } \\
\hline X1 & U1 & X akhir & Iterasi & Error \\
\hline-2.05 & -0.5 & - & - & - \\
\hline 0.11 & -0.5 & 0.5799851742 & 41 & 0.0 \\
\hline 1.65 & -0.5 & - & - & - \\
\hline-2.05 & 1 & - & - & - \\
\hline 0.11 & 1 & 0.5799851741 & 31 & 0.0 \\
\hline 1.65 & 1 & - & - & - \\
\hline-2.05 & 0.01 & - & - & - \\
\hline 0.11 & 0.01 & 0.5799851742 & 34 & 0.0 \\
\hline 1.65 & 0.01 & - & - & - \\
\hline
\end{tabular}


Tabel 12. Hasil pengujian Hopefield Modifikasi dengan persamaan

$$
x^{4}+x^{3}-0.9604 x-0.92236816=0
$$

\begin{tabular}{|c|c|c|c|c|}
\hline \multicolumn{5}{|c|}{ Metode Hopfield Modifikasi } \\
\hline $\mathbf{X 1}$ & U1 & X akhir & Iterasi & Error \\
\hline-2.05 & -0.5 & - & - & - \\
\hline 0.11 & -0.5 & - & - & - \\
\hline 1.65 & -0.5 & - & - & - \\
\hline-2.05 & 1 & - & - & - \\
\hline 0.11 & 1 & 0.9800013111 & 22 & 0.0 \\
\hline 1.65 & 1 & - & - & - \\
\hline-2.05 & 0.01 & - & - & - \\
\hline 0.11 & 0.01 & - & - & - \\
\hline 1.65 & 0.01 & - & - & - \\
\hline
\end{tabular}

Pada Tabel 7 sampai 12 menunjukkan hasil pengujian dengan metode Hopfield Modifikasi. Hasil akar persamaan polinomial dari data pengujian 0.18 , $0.58,0.98$.

Tabel 13. Hasil pengujian Newton Raphson dengan persamaan $x^{2}-0.0324=0$

\begin{tabular}{|c|c|c|c|}
\hline \multicolumn{4}{|c|}{ Metode Newton Raphson } \\
\hline X1 & X akhir & Iterasi & Error \\
\hline-2.05 & - & - & - \\
\hline 0.11 & 0.18 & 5 & 0.0 \\
\hline 1.65 & 0.18 & 8 & 0.0 \\
\hline
\end{tabular}

Tabel 14. Hasil pengujian Newton Raphson dengan persamaan $x^{2}-0.3364=0$

\begin{tabular}{|c|c|c|c|}
\hline \multicolumn{4}{|c|}{ Metode Newton Raphson } \\
\hline X1 & X akhir & Iterasi & Error \\
\hline-2.05 & - & - & - \\
\hline 0.11 & 0.58 & 7 & 0.0 \\
\hline 1.65 & 0.58 & 6 & 0.0 \\
\hline
\end{tabular}

Tabel 15. Hasil pengujian Newton Raphson dengan persamaan $x^{2}-0.9604=0$

\begin{tabular}{|c|c|c|c|}
\hline \multicolumn{5}{|c|}{ Metode Newton Raphson } \\
\hline X1 & X akhir & Iterasi & Error \\
\hline-2.05 & - & - & - \\
\hline 0.11 & 0.98 & 8 & $5.66440318 \mathrm{e}-17$ \\
\hline 1.65 & 0.98 & 5 & $5.66440318 \mathrm{e}-17$ \\
\hline
\end{tabular}

Tabel 16. Hasil pengujian Newton Raphson dengan persamaan $x^{4}+x^{3}-0.0324 x-0.00104976=0$

\begin{tabular}{|c|c|c|c|}
\hline \multicolumn{5}{|c|}{ Metode Newton Raphson } \\
\hline X1 & X akhir & Iterasi & Error \\
\hline-2.05 & - & - & - \\
\hline 0.11 & 0.18 & 8 & $-6.62617204 \mathrm{e}-15$ \\
\hline 1.65 & 0.18 & 11 & $-1.99055818 \mathrm{e}-15$ \\
\hline
\end{tabular}

Tabel 17. Newton Raphson Hasil pengujian dengan persamaan $x^{4}+x^{3}-0.3364 x-0.11316496=0$

\begin{tabular}{|c|c|c|c|}
\hline \multicolumn{4}{|c|}{ Metode Newton Raphson } \\
\hline X1 & X akhir & Iterasi & Error \\
\hline-2.05 & - & - & - \\
\hline 0.11 & - & - & - \\
\hline 1.65 & 0.58 & 8 & $2.86484918 \mathrm{e}-17$ \\
\hline
\end{tabular}

Tabel 18. Newton Raphson Hasil pengujian dengan persamaan $x^{4}+x^{3}-0.9604 x-0.92236816=0$

\begin{tabular}{|c|c|c|c|}
\hline \multicolumn{4}{|c|}{ Metode Newton Raphson } \\
\hline X1 & X akhir & Iterasi & Error \\
\hline-2.05 & - & - & - \\
\hline 0.11 & - & - & - \\
\hline 1.65 & 0.98 & 6 & $-1.34736562 \mathrm{e}-15$ \\
\hline
\end{tabular}

Pada Tabel 13 sampai 18 menunjukkan hasil pengujian dengan metode Newton Raphson. Hasil akar persamaan polinomial dari data pengujian 0.18 , $0.58,0.98$.

\section{SIMPULAN}

Berdasarkan hasil penelitian yang dilakukan metode kombinasi Backpropagation dan Hopfield Modifikasi telah berhasil dilakukan. Tingkat akurasi tersebut dipengaruhi oleh beberapa faktor yaitu pemilihan data pelatihan, nilai awal yang diberikan pada Hopfield Modifikasi terjamin dekat dengan nilai akar data pengujian. Konvergensi metode Backpropagation dapat terjebak di dalam minimum lokal. Sehingga dikombinasi dengan metode Hopfield Modifikasi dapat keluar dari konvergensi yang terjebak di dalam minimum lokal.

Kemudian dibandingkan dengan metode Hopfield Modifikasi saja. Hasil pengujian didapat jika diberikan nilai awal jauh dari nilai akar dan kompleksnya persamaan polynomial, tidak mendapatkan hasil yang akurat. Kemudian dibandingkan dengan metode Newton Raphson. Hasil pengujian didapat nilai akar akan konvergensi jika dekat dengan nilai solusinya. 
Karena nilai awal yang diberikan terlalu jauh, menyebabkan terjadinya iterasi divergen.

\section{UCAPAN TERIMA KASIH}

Penulis mengucapkan terima kasih kepada Universitas Amikom Yogyakarta yang telah memberikan dana penelitian.

\section{DAFTAR PUSTAKA}

[1] D. Mishra, P. K. Kalra, Modified Hopfield Neural Network Approach for Solving Nonlinear Algebraic Equations, Engineering Letters, 14:1, EL_14_1_23 (Advance online publication: 12 February 2007).

[2] D. Puspitaningrum, Pengantar Jaringan Syaraf Tiruan. Yogyakarta: Andi, 2006.

[3] D. Ratnawati, Penerapan JST dengan Metode Backpropagation Studi Kasus : Prakiraan Cuaca dan Kualitas Udara Wilayah DKI Jakarta, Tesis, Program Pascasarjana, Universitas Gadjah Mada, Yogyakarta. 2008.

[4] J. Ding, J. E. Gower, dan D. S. Schmidt, 2006, Multivariate Public Key Cryptosystem, Springer, USA. [13]

[5] L. Fausett, 1994, Fundamentals of Neural Networks (Architectures, Algorithms, and Applications), Prentice Hall, Englewood Cliffs, New Jersey.
[6] M. M. Gupta, L. Jin, N. Homma, 2003, Static and Dynamic Neural Networks, From Fundamentals to Advanced Theory, John Wiley \& Sons, Inc., Hoboken, New Jersey.

[7] M. Z. Riyanto, "Sistem Kriptografi Kunci Publik Multivariat", Seminar Nasional Matematika dan Pendidikan Matematika, 27 November 2010 di Jurusan Pendidikan Matematika FMIPA UNY.

[8] O. Billet, and J. Ding, "Overview of Cryptanalysis Techniques in Multivariate Public Key Cryptography", DOI 10.1007/978-3-540-93806-4_15, Springer-Verlag Berlin Heidelberg, 2009.

[9] R. Munir, Metode Numerik. Bandung: Informatika, 2008.

[10] U. M. Kaczmar, and T. Switek, "Combined UnsupervisedSupervised Classification Method", J.D. Vel'asquez et al. (Eds.): KES 2009, Part II, LNAI 5712, pp. 861-868, 2009.

[11] X. Wang, B. Yang, "An Improved Signature Model of Multivariate Polynomial Public Key cryptosystem Against Key Recovery Attack", DOI: 10.3934/mbe.2019388, http://www.aimspress.com/journal/MBE, 2019.

[12] Y. Shin, J. Ghosh, 1991, Approximation of Multivariate Functions Using Ridge Polynomial Networks, Department of Electrical and Computer Engineering, The University of Texas at Austin, 1991. 